\title{
Converting to organic farming as a way to enhance adaptive capacity
}

\author{
Maëlys Bouttes • Ika Darnhofer • Guillaume Martin
}

Received: 19 December 2017 / Accepted: 20 July 2018 / Published online: 31 July 2018

(C) The Author(s) 2018

\begin{abstract}
Farmers are facing an increasingly turbulent context, driven by volatile markets, shifting policies, and new societal expectations. Insights into farmers' adaptive capacity are helpful to understand how farmers perceive various options, and what they think is necessary to enable their farms to persist through uncertain times. We focus on dairy farmers, who have faced strong market volatility in the last few years. We conducted interviews with 20 dairy farmers who were starting their conversion to organic farming in Aveyron, France. The analysis showed that the interviewed farmers perceived organic farming as less risky, especially given stable prices and positive consumer perception. Also, they expected organic farming to increase their autonomy, especially regarding feed, thus reducing their farm's exposure to volatile input prices. Interviewed farmers were aware of technical risks linked to new production practices but were confident in their ability to manage them. Organic farming was also perceived as stimulating their learning, especially through a collective dynamic and an open exchange of experiences. The interviewed farmers expected that the higher prices of organic milk would enable them to reduce the number of cows, thus reducing their workload. This would give
\end{abstract}

\footnotetext{
M. Bouttes - G. Martin

AGIR, Université de Toulouse, INRA, INPT, INP-EI Purpan, 31320 Auzeville, France

I. Darnhofer $(\bowtie)$

University of Natural Resources and Life Sciences, Vienna,

Feistmantelstr. 4, 1180 Vienna, Austria

e-mail: ika.darnhofer@boku.ac.at
}

them more time to observe, reflect, experiment, and learn, thus not only increasing their professional satisfaction but also enabling them to better cope with changes. Overall, they perceived organic farming as an attractive option to maintain the viability of their family farm, an important motivation given their rootedness in the territory. The interviews thus showed that their decision to convert to organic farming was driven by their expectation that it would enhance their adaptive capacity, thus enabling them to better face current turbulences and future changes in the broader context.

Keywords Dairy farming · Transition · Adaptiveness · Vulnerability $\cdot$ Resilience $\cdot$ Farm management

\section{Introduction}

Farmers are facing an increasingly turbulent context. They have to cope with policy shifts, volatile commodity markets, global competition, increasingly stringent environmental regulations, and more frequent extreme climatic events, as well as changes in consumer preferences and societal expectations. Whether a farm is vulnerable to these changes or whether it is able to adapt and cope with them depends to a large extent on its adaptive capacity (Darnhofer et al. 2010). Indeed, vulnerability is generally understood as dependent on a system's exposure to hazards, its sensitivity to these hazards, and its adaptive capacity (Smit and Wandel 2006; Marshall et al. 2014). While exposure and sensitivity determine the potential impacts of a hazard, 
adaptive capacity enables to mitigate these impacts (Marshall et al. 2013). Adaptive capacity thus refers to the potential to cope with novel situations and enable adaptation, without losing options for the future (Nelson et al. 2007).

At the farm level, adaptive capacity depends on the farm's organization, e.g., the diversity of activities and marketing channels, and on the farmer him/herself, e.g., through his/her monitoring of the context and engaging in learning processes (Darnhofer et al. 2010). While a number of studies that assess adaptive capacity (e.g., Astigarraga and Ingrand 2011; David et al. 2010) focus on the activities at the farm level, this paper focuses on farmers' perception. As Flaten et al. (2005) point out, it is important to understand how farmers evaluate alternatives, to understand their frame of reference. Farmers' choices are driven by the criteria they think are important to secure the future of their farm and by their subjective perception of options. Indeed, studies have shown the importance of farmer subjectivity and of the ambition to be a "good farmer" (Burton 2004).

Recently, the strong turbulences on the milk market challenged many dairy farmers. After several decades when milk prices were regulated or the produced quantities subject to quotas, the milk market in the European Union was deregulated in March 2015. In a context of a weak demand on global markets, in France - as in much of the European Union - this liberalization contributed to a rapid and strong drop in prices paid to farmers for raw milk. Many conventional dairy farmers were faced with prices that did not cover their production costs, which led to protests organized by farmer associations across Europe and ultimately to interventions by the European Commission (European Commission 2016). As it is unclear when conventional milk prices would recover, farmers started to consider alternative markets. Some perceived entering organic markets as a promising strategy, as the price for organic raw milk was higher and has remained relatively stable following market deregulation. And indeed, organic farming may be perceived by farmers as offering levers to adapt their farms in the face of rising market turbulences (Milestad and Darnhofer 2003).

In this paper, we explore whether farmers expect that converting to organic farming will improve their ability to face changes. Our aim is to better understand what aspects of organic farming they perceive as increasing their adaptive capacity. In the next section, we briefly describe the case study region and the approach to data collection, and characterize the farms. In the "Results and discussion" section, we present and discuss how the farmers perceived that they would enhance the adaptive capacity of their farm through converting to organic farming. This covers four areas: why they perceive that converting reduces risk and uncertainty; how they feel that organic farming enhances their ability to plan, experiment, and learn; why they perceive organic farming as enhancing their ability to cope with change; and to what extent they feel they need to change to enable their family farm to persist. We conclude that the interviewed farmers perceived converting to organic farming as a way to enhance their adaptive capacity in four ways: reducing risks, stimulating learning, increasing professional satisfaction, and enabling to maintain family farms in the area (Fig. 1).

\section{Material and methods}

The case study is located in Aveyron, a mountainous department in southwestern France with very varied soil and climatic conditions. The area was selected, as it allowed us to study a group of farmers concurrently engaging in the conversion to organic farming. Indeed, until 2015, out of about 1200 dairy farms in Averyron (CA Midi-Pyrénées 2012), 40 were organic (FranceAgriMer 2016), while in 2016, some 50 farmers decided to convert. This was in large part due to a dairy that previously processed mostly conventional milk but in 2015 decided to increase its engagement in the organic milk market. After joining forces with Chinese investors, the dairy's strategy was to produce organic milk powder for the Chinese and the European market. It aimed to increase the amount of organic milk processed in its local plant from 8 to 46 million liters by 2021 (Doumayzel 2017). To achieve this aim, the dairy was actively encouraging dairy farmers to convert to organic farming by offering attractive contracts and by encouraging the advisory services of the Chamber of Agriculture to facilitate the conversion process. More broadly, the French government also promoted organic farming through its agri-environment program, offering direct payments to all dairy farmers during the first years after conversion.

For the study, we purposively selected farms to include some that were closer to and some that were further away from organic practices. We thus included larger and smaller farms, as well as more or less 
Fig. 1 In the interviews with dairy farmers, we identified four mechanisms through which they expect organic farming to enhance their adaptive capacity: (a) by reducing risks, esp. due to higher and more stable milk prices; thus, while conventional farmers felt like balancing on a wire, they expect organic to be like a more comfortable suspension bridge; (b) by stimulating learning, especially through collective dynamics and an open exchange of experiences with other farmers; (c) by increasing professional satisfaction thanks to a lower workload; (d) by enabling farmers to maintain their family farm, which is an important motivation given their rootedness in the territory (illustration by Z'Lex for the authors)

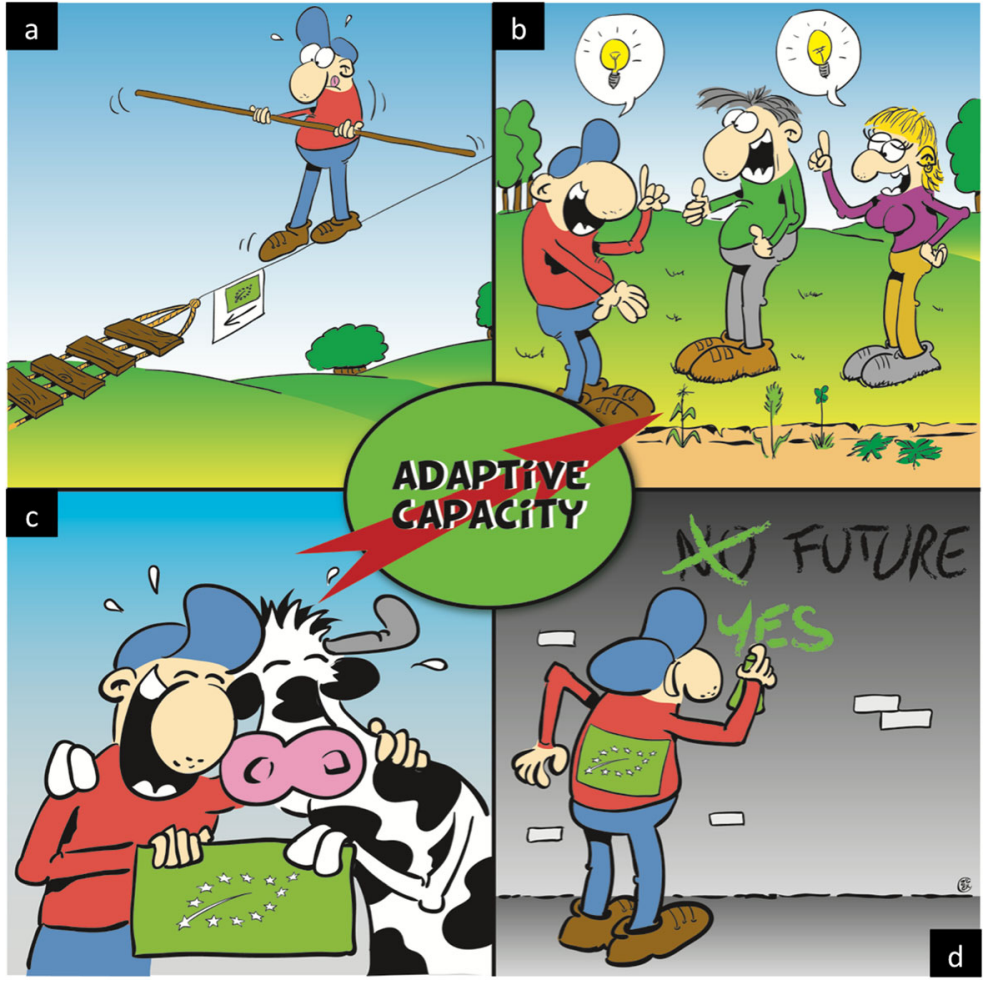

intensive farms (classified based on the share of maize in the utilized agricultural area). Our aim was to capture a wide range of perceptions of how organic farming may enhance or reduce adaptive capacity, especially compared to conventional dairy farming. To identify farmers, we initially asked local organic consultants who were involved with farmers engaging in conversion, and then identified additional farmers through snowballing. We stopped data collection after 20 farmers, as data saturation was reached.

The 20 farms covered a range of sizes in terms of agricultural area (36-145 ha, with a mean of 81 ha), of herd size (35-125 heads, with a mean of 56 dairy cows), and of produced milk (200,000-800,000 kg/year with a mean of $390,000 \mathrm{~kg}$ ). One farm had a milking robot; two farms processed part of their milk on-farm; and six farms were engaged in direct marketing. As an indicator of land-use intensification, we used the share of maize in the agricultural area, which varied from 0 to $42 \%$ (with a mean of 16\%), indicating that on some farms, maize silage was relied upon to feed their cows, whereas on others, milk production was mainly pasture-based. Almost half $(45 \%)$ of the farms had another on-farm activity (pig, sheep, or beef cattle breeding, potato or tobacco cropping). Most farmers had another person working with them on the farm, often a family member (1-3 people, with a mean of 1.9). The interviewed farmers ranged from 29 to 66 years of age (with a mean of 47 years) and had been farming for 5 to 41 years (with a mean of 20 years). The sample thus includes a broad range of experiences, from young farmers to some who will soon retire. All interviewed farmers were deeply rooted in the territory, as their families had been managing the farm for several generations.

To collect farmers' perceptions regarding their conversion to organic farming, we used semi-structured interviews. These provide rich qualitative data on farmers' knowledge, reasoning, views, and perceptions (Miles and Huberman 1994). A preliminary list of questions was drafted based on issues raised in the literature, as well as during participant observation at collective training sessions and at farm visits organized by the Chamber of Agriculture. This preliminary list was refined through discussions with organic consultants. The interviews covered three broad areas. Firstly, farmers' goals and expectations, the constraints they perceived, and the uncertainties they had for their farm and for dairy farming on their territory. Secondly, we asked about farmer networks and sources of information, i.e., professional actors with whom they were in regular 
contact, as well as their involvement in professional networks. Thirdly, we raised questions specific to their decision to convert to organic farming, i.e., at what time they started to think about conversion and why; their perceptions of other organic farmers; the reactions by neighboring farmers and by their family when they shared their thoughts about converting to organic farming; and the doubts and risks they perceived about organic farming. The interviews were carried out during spring and summer 2016, as all the farmers started their conversion in spring 2016. The interviews lasted 1-4 h. They were recorded and transcribed in full.

To analyze the interview transcripts, we took an abductive approach (Alvesson and Sköldberg 2009). We started with the four dimensions defining adaptive capacity that were proposed by Marshall et al. (2014): perceptions of risk and uncertainty; skills for planning, experimenting, learning, and reorganizing; the ability to cope with change; and the level of interest in change. As these dimensions were developed in the context of adaptation to climate change, we revised them iteratively based on the interviews, to operationalize them in the context of market volatility and the conversion to organic farming. In the analysis, our aim was not to assess the level of adaptive capacity of the individual farms but to understand how the interviewed farmers perceived organic farming as enabling them to enhance their adaptive capacity.

\section{Results and discussion}

Organic farming to reduce risk

As Marshall et al. (2014) point out, to be able to cope with and adapt to change, it is fundamental to manage the risks associated with change and to be willing to engage in a new path if it seems promising, even if its outcome is uncertain. In the context of our study, it was important to understand both the risks that the interviewed farmers perceived in relation to either continuing as conventional farmers or converting to organic farming (Xu et al. 2018). This allows to understand why - even if organic farming is perceived as risky and uncertain - they perceived it as more promising within the current context.

Conventional farming was seen as risky for two main reasons: the persistent market turbulences had led farmers to question whether it was economically feasible to continue as conventional dairy farmers and the "get big or get out" approach to increase profitability seemed to trap them in a vicious circle. The interviewed farmers perceived the prices for conventional raw milk as low and erratic. Most of the interviewed farmers did not expect such a strong drop in prices, nor such a prolonged crisis, following the abolition of the quota system: "we expected problems with the end of the quota, but not as hard!" (farmer 16), "[that prices would] drop that low again, no, I really didn't believe it!" (farmer 9). While prices for conventional raw milk might increase in the future, they expect them to remain unpredictable and erratic. The market turbulences have thus led them to question whether the conventional system was viable for them: "as long as milk worked rather well, the question [of conversion] did not really arise. But now, it is especially the financial aspect that makes you think" (farmer 3).

The perception of the low and erratic prices as problematic is compounded by the perception that conventional farming does not offer much room to maneuver, giving farmers the feeling of being trapped: "if one is in this vicious cycle, there is no choice" (farmer 17). Indeed, it seems that the only way to cope with low prices is for the farm to grow, to increase the volume of milk produced, and to take advantage of the economies of scale. However, this is not seen as a promising longerterm strategy: "to compensate prices through volumes, after a while you have to stop" (farmer 15). This is partly because the interviewed farmers do not feel that they live in a region with a comparative advantage in milk production: "we're poorly placed in the Aveyron to produce conventional milk without quotas, other regions can produce more milk and cheaper" (farmer 11) and partly because the farmers perceive that constantly pushing the cows to produce more milk, and the land to produce more crops, is problematic: "we had reached the end of our rope, our harvests were not high enough, we were exhausting our soils" (farmer 9). The interviewed farmers were thus increasingly aware that they needed to change "something": the milk crisis following the abolition of the quota system had led them to realize that continuing as conventional farmers was not promising and was increasingly risky. However, given that in this region farms have been handed over within families over many generations, farmers have a high commitment to continue this tradition by identifying ways to secure the future of their family farm.

In this context, organic farming was perceived as offering a promising alternative. A conversion shifts 
the strategy from focusing on quantity to focusing on quality: "to pull through, we have to stop the high volumes and focus on quality" (farmer 10). Producing milk that complies with organic quality standards allows securing higher prices and engaging in markets that seem more stable: "the tipping point for us was that it is a system that seems more sustainable, where we can try to make predictions not just on the short-term, but also on the medium-term" (farmer 12). And indeed, they feel they have "a positive perspective for at least five years" (farmer 14). This medium-term perspective is linked to the contracts between the Chinese investors and the local dairy. It is also linked to the farmers' awareness of the strong consumer demand for organic products in France, in Europe, and on the global market: "consumption, nowadays it is organic" (farmer 1), "[organic] now seems established [...] these are no longer purchases in response to a food safety crisis. The people are getting used to eating healthier" (farmer 20).

Considering the production system, the interviewed farmers perceive organic farming as instrumental in their efforts to reduce expenditures for inputs and to increase their autonomy by focusing on feed produced on-farm: "I think that the first savings will come from a reduction of inputs, we will have to be as autonomous as possible" (farmer 18). Increasing feed autonomy is an important lever to reduce farm exposure to the volatility of input prices and to the cost-price squeeze, which burdens farmers when input costs remain high but milk prices are low or volatile (Van der Ploeg 2000).

However, organic farming is not devoid of uncertainties. The farmers cannot be sure of the future development of organic markets, so that they were aware that converting was "a bet on the future" (farmer 18). The interviewed farmers were aware that more farmers might convert to organic farming, including in areas where the climate enables milk production at a lower cost: "if Ireland goes organic, we're in trouble" (farmer 6). If the supply of organic milk increases, then "in 20 years [...] organic farming will become ordinary" (farmer 17). Also, with increased supply, it might be more difficult to secure markets: "maybe in ten years, the Chinese will have said goodbye to us" (farmer 14). Also, some farmers were concerned about the evolution of organic standards: "if they become too flexible, then organic will become meaningless to consumers" (farmer 7).

Another uncertainty concerned the direct payments, which are offered to organic farmers within the French agri-environment program. ${ }^{1}$ However, the implementation of the agri-environment program in the framework of the CAP 2014-2020 was delayed, and it was uncertain how the maximum payment per farm would be set by the regional authorities. The interviewed farmers perceived the payments as reducing the risk during the conversion period: "as long as there are the payments, the help for the conversion, I don't take a big risk, I don't think so" (farmer 2). However, the farmers could not be sure about the payments' level, nor about their duration. Indeed, during the collective training sessions with farmers, which we participated in, the local consultants of the Chamber of Agriculture were not only reporting delays in the disbursement of the direct payments and uncertainties in the payment ceilings but also questioning whether there would be payments beyond the first 5-year period. Indeed, the budgets for organic farming set by the Ministry of Agriculture are capped, and the number of conversions far exceeded expectations (CGAAER 2017). However, the interviewed farmers were not too worried: "it should work without the payments, they are the cherry on the cake" (farmer $3)$.

At the same time, the interviewed farmers were well aware that they would face a number of challenges on the farm: "I'm apprehensive to have dirty crops" (farmer 9); “dock [Rumex sp.] will be a problem" (farmer 15). A few interviewed farmers - especially those that were rather intensive - seemed somewhat worried about this plunge into the unknown: "I'm afraid of stopping maize which is the basis of my cows feeding" (farmer 1); "Will I be up to it?" (farmer 15); "I do not really know where I am going" (farmer 8). The change seemed to be easier for those farmers who were "almost organic anyway": "my production practices weren't far from organic, and this makes the leap easier" (farmer 20); "we didn't follow the [organic] principles, but we were not intensive, we never pushed our animals too far, nor our land" (farmer 14). Thus, the interviewed farmers were aware of the risks linked to the changes in production methods, yet confident in their own capacity to manage the demands of organic farming practices: "our neighbours managed it, so we too will manage it" (farmer 9).

\footnotetext{
${ }^{1}$ In 2016, the expected payments for organic farms were in the range $35-300 € /$ ha (the payments depend on land use, e.g., 35 or $130 € /$ ha for pastures and $300 € /$ ha for annual crops or pastures with more than $50 \%$ of legumes) during the first 5 years following the conversion and in the range $35-160 € /$ ha for the next 5 years (FNAB 2018).
} 
Overall, the interviewed farmers perceived risks and uncertainties in the future of both conventional and organic dairy farming (Fig. 2). However, over the short and medium term, organic farming was perceived as less risky, as milk prices were higher and more stable and consumer perception more supportive, and because at the farm level, it offers the opportunity to increase autonomy, especially regarding feed (Coquil et al. 2014; Benoit et al. 2017). Thus, in the context of low and variable prices for conventional milk, organic farming is perceived as an opportunity, offering better prospects for the future. This is quite different from former studies, where converting to organic farming was considered risky, often due to the lack of technical knowledge (Padel 2001). Our study also shows that farmers carefully assess the trade-offs between external factors, such as product quality requirements and prices, and internal demands, such as risks tied to new production techniques. Farmers are thus carefully observing changes on markets, in regulations, and in technical production practices (Lamine 2011; Chantre and Cardona 2014) and, given the developments they perceive as most likely, strive to anticipate how their farm could fare well in the future.
Organic farming to stimulate learning

To cope with and adapt to change, it is essential to experiment and learn, so as to prepare for the future (Marshall et al. 2014). These skills are linked to individual creativity, i.e., how personal preferences, on-farm resources, and the specific advantages of the region can be combined. But there is also a collective dimension, i.e., sharing experiences among peers and learning from each other (see Olsson et al. 2008).

A conversion to organic farming was widely perceived by the interviewed farmers as a welcome professional challenge. In conventional farming, the farmers had "recipes" that they knew worked well, and they implemented them each year, with only minor adjustments. Some interviewed farmers said they were tired of this routine and welcomed a new challenge: "I need goals, I didn't have any anymore" (farmer 18). In organic farming, when they will be facing a problem, there will be no synthetic pesticides or fertilizers that can be applied to correct mistakes. Farmers thus perceived organic farming as farming without a safety net: "you don't have the product or the stuff which will save you" (farmer 14). And, importantly, they look forward to the
Fig. 2 The interviewed farmers perceived risks and uncertainties in the future of both conventional and organic dairy farming, including (a) price volatility, (b) the pressure to grow and invest, (c) the technical production risks on the farm, and (d) the uncertain consumer demand. Overall, organic farming was perceived as reducing external pressures and increasing autonomy, hence reducing risk (illustration by Z'Lex for the authors)

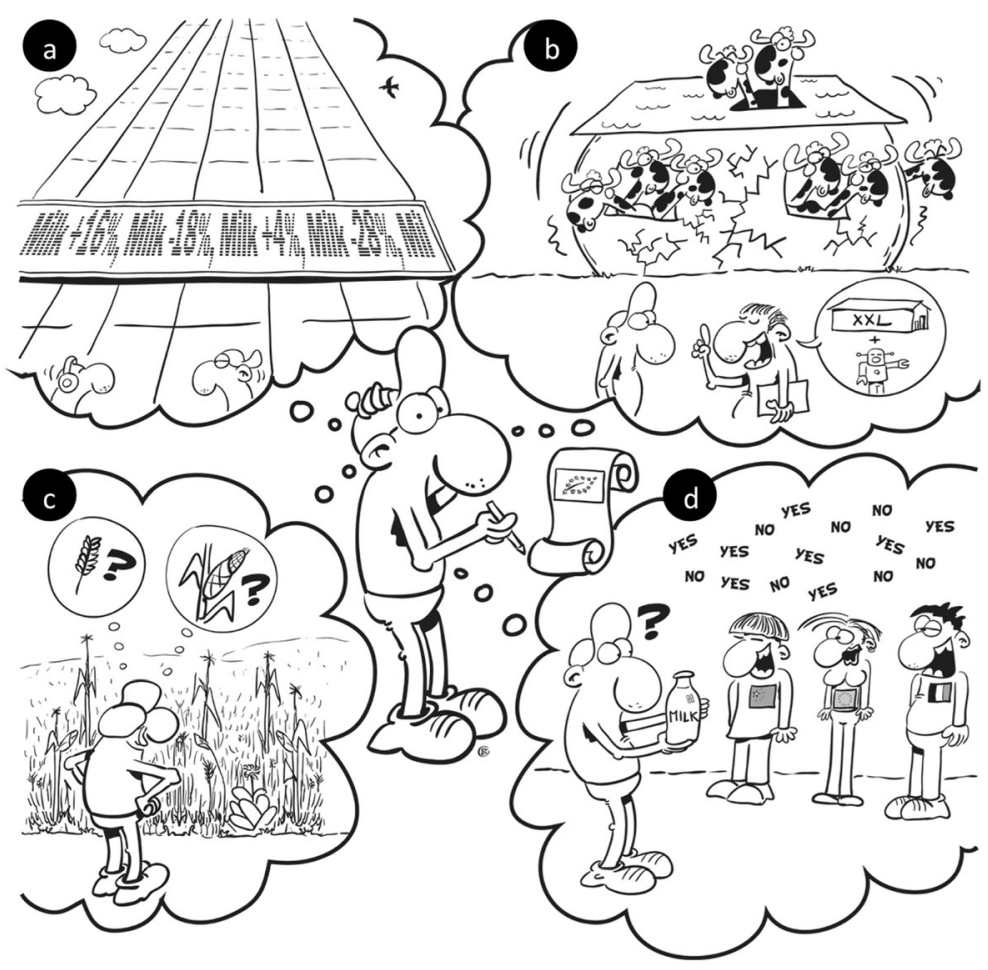


challenge: "there is no parachute or umbrella to protect you. Before anything else, it requires us to observe nature, and that will be a real treat" (farmer 15). Converting to organic farming was thus perceived as an opportunity to develop new skills: "you have to learn again how to look closely, to listen, to work with nature; and not exploit her, not negate her" (farmer 16). Organic farming is perceived as technically more challenging, and the farmers looked forward to mastering the challenge for their own sense of achievement: "in conventional we are satisfied, but if we manage without polluting, it will be all the more gratifying" (farmer 1), as well as for peer recognition: "now we want to demonstrate to neighboring conventional farmers that our results will be just as good, even being organic" (farmer 7). The changes in the production practices were thus perceived as a welcome learning opportunity: "I'll have to go back to school for a bit, that's clear" (farmer 4).

Their openness to learn new production methods and their ability to face their apprehensions were strengthened by the support they received from organic consultants from the Chamber of Agriculture. These consultants were trusted and widely perceived as "good" consultants, which reassured farmers that they would get reliable advice. It was also important that the Chamber of Agriculture designed a collective learning process (Fig. 3). Within this process, the farmers who were considering a conversion to organic farming were invited to visit several local organic dairy farms. Through these visits, they discovered a stimulating, dynamic network of organic farmers who were willing to openly share their experiences: "there are more exchanges than in conventional farming" (farmer 15). Importantly, the visited farmers did not hesitate to talk about their doubts and discuss mistakes they had made, which encouraged the interviewed farmers to be open too: "it allowed us to talk about it, when something had gone wrong, to say 'I messed this up, don't do it like that,' or: 'I tried this to correct the mistake,' or: 'I did this, it works well.'” (farmer 1). This was a welcome contrast to conventional networks, where the interviewed farmers perceived other conventional farmers as often reserved and individualistic.

These results are well in line with previous studies that have highlighted that conversion to organic farming demands new skills (Cranfield et al. 2010). Indeed, the interviewed farmers appreciate the conversion to organic farming as an opportunity to learn, as a welcome opportunity to break out of their routine, and as an opportunity to face a new challenge. Indeed, organic farmers often

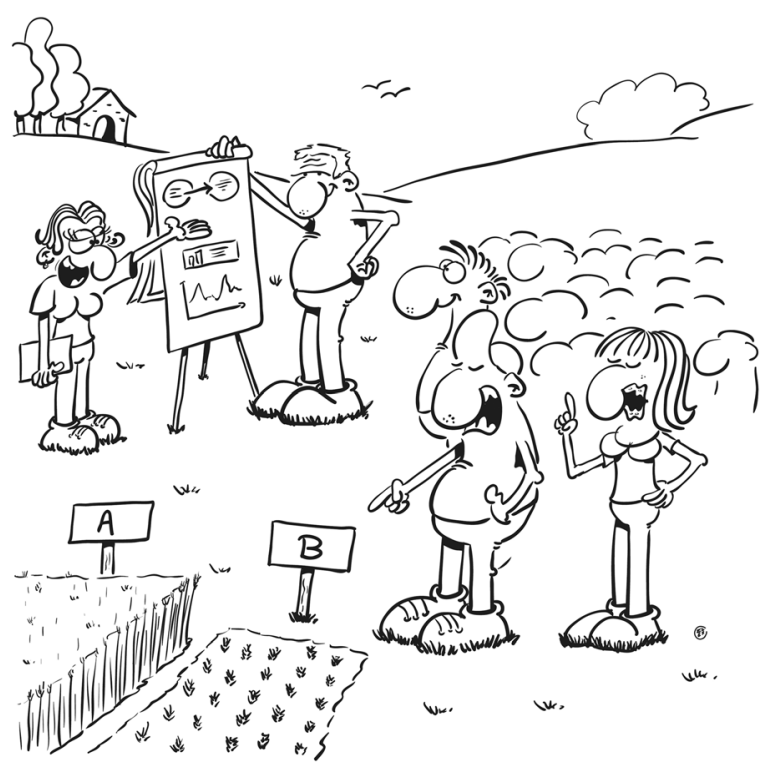

Fig. 3 Organic farming is perceived as an opportunity to learn. This is illustrated by a farm visit where consultants show the results of two trials to a group of farmers, who listen and discuss their own observations. For the interviewed farmers, the collective learning process set up by the consultants and the joint visits to established organic farmers were key to strengthening their confidence in their own ability to face the technical challenges involved in the conversion to organic farming (illustration by Z'Lex for the authors)

experiment, which allows them to keep their practices attuned to local specificities and adaptable to changing economic, social, and ecological conditions (Vogl et al. 2015). Both learning and experimenting can be enhanced through a group process, where production methods are proposed and discussed, insights integrated, practices implemented on individual farms, and the outcome reflected on collectively (Lamine 2011). Such exchanges are stimulated if there is trust in a group: trust in experts' information and in peer's experience. Their openness to face a new professional challenge and to engage in experiential learning and the networks created through the collective processes all contribute to enhancing their adaptive capacity.

Organic farming to increase professional satisfaction

The ability to cope with change is linked to the mental health and the emotional buffer of individuals, which enables them to absorb the impact of change (Marshall et al. 2014). It refers to the ability to see the positive aspects of change and to actively engage with it, rather than perceiving change as a burden to be endured. In the 
interviews, the emotional burden of feeling trapped in the conventional system was often mentioned, and farmers expected that converting to organic farming would contribute to improving their work satisfaction.

Some farmers pointed out the emotional burden linked to the low conventional milk prices, which negatively affected their financial status: "because at night, you wake up, you ask yourself the question: how are we going to pay the bills? That's a problem, a big problem" (farmer 9). Other farmers pointed at the high workload they have as conventional farmers, linked to the pressure to increase milk production, to cover the costs despite low milk prices: "we were trapped in our system [...] to do a lot of milk, and behind that: a lot of work" (farmer 16). The farmers were aware that this was not just a momentary labor peak, but systemic: "we take it on, and then we notice that we're in a vicious cycle" (farmer 20). The high labor load is also problematic as it prevents farmers from engaging in important activities: "last winter I could not attend any training courses all winter, as I was alone on the farm and overloaded" (farmer 13). Some farmers perceived the conversion to organic farming as an opportunity to reduce the number of cows, and thus their workload: "why not reduce our herd, maybe do better: more [time for] observation, better milk quality" (farmer 20). Another hoped it would contribute to improving his quality of life: "maybe we will have more free time [with] fewer cows, and we will be more peaceful, relaxed" (farmer 12).

These expectations of a better work-life balance built on what they observed during the on-farm visits organized by the Chamber of Agriculture and the organic consultants. There, they met organic farmers who were satisfied and unworried: "we see them in good spirits, serene in their work and with their finances" (farmer 9). When they compared their own situation as conventional farmers with these organic farmers, they realized the contrast: "farmers who have beautiful fields, who work well, and who, in the end, are more relaxed than you are" (farmer 14).

The interviewed farmers also pointed out that some practices in conventional farming were becoming an emotional burden, and they increasingly felt reluctant to engage in them. In particular, they pointed out their dislike of having to spread chemicals on their fields: "having to attach the sprayer irritated me" (farmer 15); "the products, all that; we are not proud when we apply the products" (farmer 1). They were worried about the impact on their soils: "the chemical fertilizers, when you look it up on the internet: it doesn't help the soil. In the end, on the long term, it destroys more than it helps" (farmer 4). Some started to feel that the chemicals were affecting their health: "last time I did maize [...] I put on the full protective suit, as if I went to the moon, with the mask and all. But my head [hurt], I did not feel well" (farmer 14); "if I open a can of herbicide, I get a headache" (farmer 4). The farmers were concerned not only about their own health but also about the impact of potential chemical residues on consumers: "there are human beings at the end of the chain, who will get it all" (farmer 15). They looked forward not to have to "spread all sorts of stuff on the fields, no longer having to have a cupboard full of chemicals" (farmer 16); "we won't poison ourselves anymore, we won't poison anybody anymore" (farmer 2).

The interviewed farmers felt increasingly apprehensive about using agrichemicals, especially given the reports in the media on environmental problems related to conventional farming: "I was never motivated to use the sprayer, we know very well that it is harmful" (farmer 12); "I think that the mentality is changing, even those who don't convert to organic farming think about reducing their use of chemicals" (farmer 9). The public pressure has led one farmer to abstain from using standard safety measures: "I have started not protecting myself when applying chemicals, to show the tourists that it's not dangerous" (farmer 7). They also faced these critiques at a personal level, when they have had to justify their practices with non-farming neighbors and tourists: "this context, with the pressure to protect the environment, it is really unbearable: we are always suspected to be environmental criminals [...] I exaggerate, but it is really a burden" (farmer 19). Indeed, the farmers would like to be valued and respected for their work: "that people see that in agriculture we don't do a dirty job, that the people from the cities appreciate us a bit [...] I would like that the people take a look, that they are curious" (farmer 13); "it is important that we regain a positive image" (farmer 12).

The interviewed farmers expected that organic production practices would enable them to work in closer conformity with their personal values: "it will be a pleasure to work without chemicals" (farmer 1), to have "respect for nature" (farmer 15). "As an organic farmer, I will be better able to look myself in the mirror" (farmer 17). It will enable them to improve their own and consumers' health: "to be in harmony with myself, with what I preach, to make a healthy product" (farmer 20). 
And they already received positive feedback: "when you tell people that you are converting, people say: "Great! That's good!" (farmer 1).

While the organic production practices are considered by the interviewed farmers to be more environmentally friendly, they are aware that they will still have an impact on the environment: "I would like to see [agriculture] without ploughing, natural pastures, but I do not know if this exists. It is absurd to convert to organic farming and consume more fuel" (farmer 13). They thus feel there are trade-offs: "does it really make sense to have four passes with the harrow in organic farming, rather than use a tiny amount of chemicals?" (farmer 7). Similarly, they find that producing organic milk for the global market is questionable: "it is a pity to produce milk that goes to the other end of the planet. But for now, to convert to organic farming, we don't have a choice" (farmer 17).

Moreover, while consumers and non-agricultural neighbors have a positive image of organic farmers, their peers-many of whom are conventional farmers - still perceive organic farmers as odd: "the neighbours, the other farmers tell us that we are a bit mad" (farmer 11). Many conventional colleagues question whether organic farming even works, so that interviewed farmers were faced with numerous questions and warnings: "how will you feed your dairy cows and all, from what will you live?" (farmer 20); "you won't have any grass next year! You won't have grass for silage!" (farmer 20); or “it won't work! Your productivity will drop too far. All that you will gain in price, you will lose in volume, because your cows will only produce half as much" (farmer 1). Not only were many conventional peers doubtful, a number of interviewed farmers also faced the doubts of their family members (i.e., their parents or children), as especially parents tend to perceive organic farming as a step backwards. Despite this, all interviewed farmers felt that the perception of organic farming was changing: "the mentality evolves: today, if you are organic, it's not that you are a revolutionary [as in 1968], it's that you think about things" (farmer 4).

The interviews highlighted the emotional dimension tied to production practices. Many of the interviewed farmers were emotionally burdened by financial challenges, by a high workload, or by concerns about the potential impact of the use of synthetic chemicals on their own health and on the environment. They also tended to be emotionally burdened by the negative reports in the media, the negative public image of conventional farming, and the need to justify their practices to non-farmers. All of these reduced their work satisfaction, which is particularly problematic as for most, being a farmer was a vocation rather than just a "job." In many ways, converting to organic farming was linked to the expectation that it would enable them to enjoy their work (Fig. 4), a satisfaction heightened by the positive feedback they already receive for their decision to convert. The importance of such "pleasures" when changing towards more ecological farming practices has been emphasized by Barbier et al. (2015). Indeed, farmers want to be proud of the work they do, which requires a fit between their aspirations and the daily reality of being a farmer (Dessein and Nevens 2007). Work satisfaction and being proud of their work contribute to emotional health, which is essential to enable farmers to cope with change and recover from setbacks.

Organic farming to maintain the family farm

The fourth dimension of adaptive capacity identified by Marshall et al. (2014) is the level of interest in change.

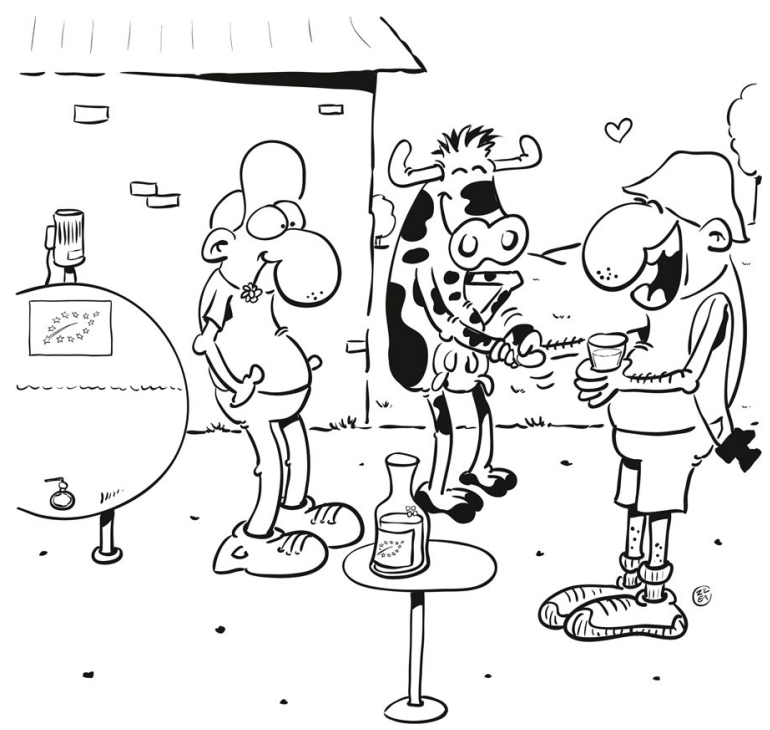

Fig. 4 The farmers expected that converting to organic farming would allow them to enjoy their work more, thus enabling them to cope with change and recover from setbacks. This is illustrated by a farmer who is serene and satisfied, even if he produces less milk, as shown by the partly filled tank. His work satisfaction is enhanced by the tourist enjoying a glass of his fresh organic milk, indicating the positive feedback from consumers and the positive image of organic farming in the media (illustration by Z'Lex for the authors) 
This is related to flexibility and to the ability to explore different options (Darnhofer et al. 2010; Astigarraga and Ingrand 2011). People interested in change observe trends in the broader regional, sectoral, and societal context; can assess possible consequences; and identify a range of alternatives to face change. The aim is not to just react once change has occurred but to be pro-active, to recognize opportunities, and to be able to seize them.

Given the problems they were facing on their own farm, as well as the changes in public perception of conventional farming, the interviewed farmers were aware that they needed to change: "we had to find something: change production or converting, we don't have the choice anymore!" (farmer 20); "I reached a point where I had to get out of conventional farming, I had to find an exit" (farmer 4). The farmers have thus been looking for options: "find solutions to be able to continue" (farmer 13). With the dairy offering contracts to organic farmers, conversion was a welcome opportunity: "we had been thinking about it for a long time, we kind of jumped on the opportunity" (farmer 14). And indeed, several interviewed farmers perceived conversion to organic farming, now that there was an organic dairy in the region, as an opportunity not to be missed, as a "train that you need to catch, because it won't come around again" (farmer 9).

The interviewed farmers expressed a strong attachment to the place, to maintaining their farming activity in this territory. They were all born on the territory and grew up in the local farming tradition, on farms that had been in their family for several generations: "to avoid losing what my father had done with the family farm" (farmer 4). They were also committed to continue to be part of the local community. Converting to organic farming was thus not seen as a critique of conventional farming and was not seen as jeopardizing their solidarity with other farmers: "it's not because I'll be organic that I will say something bad about my conventional neighbour" (farmer 18); "I think that we need a bit of everything. We need organic, and we need conventional, because, after all, we need volume to feed the planet" (farmer 19). The conversion is thus not a matter of ideology: "we are not born organic, we don't eat organic, our parents don't eat organic" (farmer 12); "we evolve in our head, but I am not born with this mentality" (farmer 5). To most of the interviewed farmers, converting to organic farming is primarily a promising strategy to maintain their family farms, while adapting to changes in the broader context. Such changes were required in the past and will be necessary in the future (Fig. 5).

That the interviewed farmers are open to change is expressed by how they look forward to the upcoming challenges: "it allows us to energize us, in our heads, see other horizons, think about other things. I myself, I really need this to work" (farmer 20); "it's a new challenge, it renews my motivation, rather than continue what we've been doing, routine" (farmer 3). This desire to change and to take up a new challenge is embedded in a wider awareness that practices need to be questioned and renewed regularly, as getting stuck in a routine can be dangerous: "the worry of the farmer - me included, but it seems to me that I stepped out - is to get stuck in a rut. We are so stuck in our habits, we don't look back.

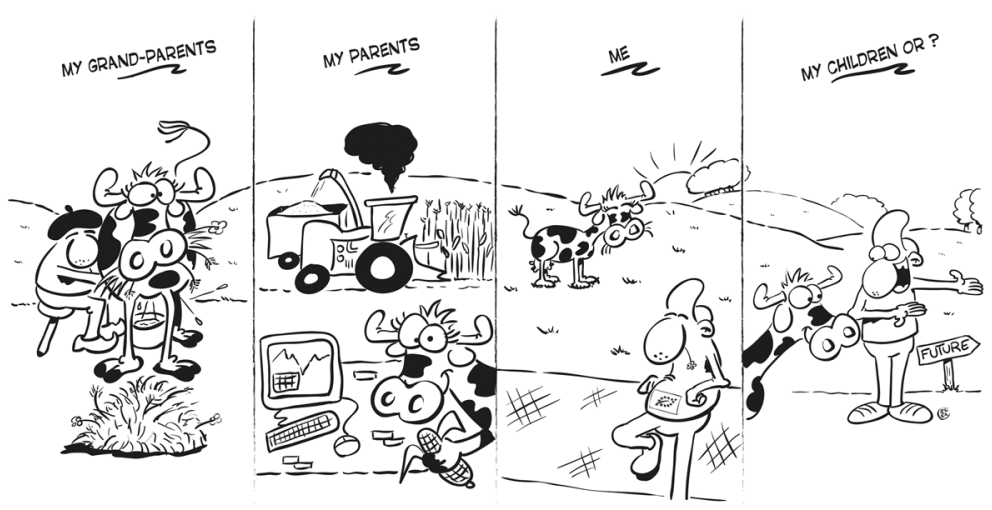

Fig. 5 The farmers were aware that to persist over the long term, a system needs to change with its context. Thus, over the past two generations, dairy farmers adapted to maintain their family farm. While the current farmer's grandparents milked their cows by hand and the cows were fed with hay, the next generation mechanized and used information and communication technologies, and cows were fed with maize. The current farmer converts to organic farming and the cows are grazing. What will happen in the future is unknown but likely to be different from today (illustration by Z'Lex for the authors) 
We know we have to put that much nitrogen fertilizer and that much of this. It's a schema. And one does not want to get out of the rut. It feels comfortable in there. But the problem is: one sinks in" (farmer 17).

Given the changes in the broader context, farmers were aware that they needed to implement changes on their farm, if they wanted to ensure its continuity. These results are in line with studies of farms transitioning towards more ecological practices, which showed that transitions were often initiated by farmers perceiving their current practices as problematic and actively looking for alternatives (Lamine and Bellon 2009; Coquil et al. 2014; Chantre et al. 2015). Changing practices is thus recognized as necessary to keep in tune with a changing economic and social context (Goulet and Vinck 2012). The interviewed farmers were aware of the interplay between change and persistence and thus were interested in actively shaping changes on their farm, to avoid getting caught in routines, which were out of synch with society's expectations of agriculture.

\section{Conclusion}

While looking for a way out of the crisis in conventional dairy farming, the interviewed farmers perceived organic farming as an attractive option, particularly because it can enhance their adaptive capacity. They regarded organic farming as a way to enhance their adaptive capacity through four mechanisms: reducing risks, stimulating learning, increasing professional satisfaction, and enabling them to maintain their family farm. The farmers perceived organic farming as less risky due to higher and more stable prices for organic milk, and by enabling them to increase their feed autonomy and thus reducing their farm's exposure to volatile input prices. While farmers were aware that on the short term they would face technical risks linked to implementing new, unfamiliar production practices, they also felt that converting would lower their long-term risks, as organic farming is in line with consumer expectations. Moreover, the interviewed farmers were confident that they would be able to master organic production practices, because they trusted the organic consultants and because the Chamber of Agriculture set up a collective learning process, so that they could build on each other's experience rather than having to face the challenge alone. Learning is also linked to professional satisfaction, as many of the farmers were looking forward to a new challenge that would enable them to break through the repetitive routine they faced as conventional farmers, giving them an opportunity to learn and master new skills, and thereby demonstrate their professional expertise and competence. They also expected their professional satisfaction to be increased because they would be under less pressure and have more time to observe and reflect, thereby enabling them to better cope with changes. Indeed, the higher prices of organic milk and the higher feed autonomy would enable them to secure their income with fewer animals, thus reducing labor demands. Thus, they perceived that converting to organic farming would enable them to maintain their family farm, which was important to them, both to maintain the family's and regional traditions and because to them farming is not a "job" but a preferred way of life.

This study, based on a group of farmers who have just started their conversion to organic farming, highlights the aspects that were decisive in their decision to engage in the conversion process. While the fact that the local dairy became involved in the organic milk market was doubtlessly important and is likely to have tipped the balance for a number of farmers, the root cause seems to be their increasing dissatisfaction with conventional farming. Indeed, a farmers' decision on whether or not to convert is deeply influenced by his/her satisfaction with the current strategy and the satisfaction he/she expects to derive from an alternate strategy. In this study, the farmers were clearly questioning the dominant strategy in conventional farming, which pushes farms to enlarge, increase the number of dairy cows, and intensify so as to increase the amount of milk produced. The farmers point out that in this region it leads to a high debt load and a high labor load, while exhausting the cows and depleting their soils. Moreover, some of them feel that the use of agrichemicals threatens their health and is perceived negatively by consumers. A conversion to organic farming thus might well be initiated by inviting farmers to openly reflect on their current production system and encourage them to honestly assess whether they expect that it will secure the future of their farm, regarding, e.g., financial stability, protection of natural resources, and quality of life. As was the case for this group of farmers in the Aveyron, organic farming might then emerge as a way out of a production system that offered them only a narrow "room for manoeuvre."

This study also highlights that a conversion to organic farming should not just be advocated by highlighting economic benefits or that the production practices are in 
line with societal demands for environmental protection. While these are important considerations, this study shows that the subjective, personal satisfaction of the farmer also plays a crucial role, especially if organic farming is perceived by the farmer as enabling him/her to achieve his/her professional ambitions. These may be linked to organic farming encouraging farmers to engage in a collective learning process and thus interacting with peers in a close network; to have more time to think about interactions on his/her farm, thus stimulating, e.g., experiments to improve the nutrient flows, or to develop a new on-farm activity; or mastering technical challenges and thereby boosting their feeling of proficiency and self-efficacy. The study thus highlights the importance of avoiding to assume that farmers are rational decision makers narrowly focused on economics and/or optimizing productivity, and acknowledging that farmers have a complex and interacting set of values and preferences, ideals and motivations, ambitions, and emotional drivers. It might thus be helpful to present organic farming as a way that enables farmers to combine traditions, societal demands, and personal ambitions, rather than just as a set of production practices.

In their assessment of organic farming, the interviewed farmers integrated very different elements, such as expected development of markets, regulations, demands by consumers and citizens, perception by peers, impact on emotional health, likely technical challenges, learning requirements, and the richness of the collective learning process. As this study is based on farmers' perceptions at the beginning of the conversion process, it would be important to assess whether and how their perceptions of organic farming change in subsequent years. Indeed, the management of a family farm is based on complex and dynamic interactions between very different elements, and the relative importance of individual elements or dynamics is likely to change over time. This highlights the importance of adaptive capacity to ensure the long-term persistence of a farm. If organic farming enhances this adaptive capacity, this may be an important aspect to highlight to farmers considering a conversion, as many family farmers aim not so much to maximize their profits or yields on the short term, than to ensure the persistence of their farm over the long term.

Acknowledgments Thanks to specific scholarship from INRA, Toulouse INP, and Ecole des Docteurs Toulouse, Maëlys Bouttes had the opportunity to stay at the University of Natural Resources and Life Sciences, Vienna, to work on this paper. The authors wish to thank the farmers who generously gave their time and shared their thoughts during the interviews. We thank Z'lex, an organic dairy farmer and cartoonist in Aveyron (France), for his insightful cartoons that were created in discussions with the authors. We thank Stéphane Doumayzel and Sandrine Viguie from the Chamber of Agriculture, Johann Kévin Galtier and Maxime Vial from APABA, and Nicolas Juillard from BTPL for their support with the implementation of the surveys. We are grateful to the anonymous reviewer and to the editor for their insightful comments and suggestions on an earlier version of this paper.

Funding information Open access funding provided by University of Natural Resources and Life Sciences Vienna (BOKU). This study was funded by INRA and the Midi-Pyrénées region as part of the ATARI project and Maëlys Bouttes's $\mathrm{PhD}$ project and by the French ANR Agrobiosphère program as part of the TATABOX project (ANR-13-AGRO-0006).

Open Access This article is distributed under the terms of the Creative Commons Attribution 4.0 International License (http:// creativecommons.org/licenses/by/4.0/), which permits unrestricted use, distribution, and reproduction in any medium, provided you give appropriate credit to the original author(s) and the source, provide a link to the Creative Commons license, and indicate if changes were made.

\section{References}

Alvesson M, Sköldberg K (2009) Reflexive methodology: new vistas for qualitative research. SAGE, Newcastle upon Tyne

Astigarraga L, Ingrand S (2011) Production flexibility in extensive beef farming systems. Ecol Soc 16:7. https://doi.org/10.5751 /ES-03811-160107

Barbier C, Cerf M, Lusson J-M (2015) Cours de vie d'agriculteurs allant vers l'économie en intrants : les plaisirs associés aux changements de pratiques. Life course of farmers going to the economy in inputs: pleasures associated with changes in practices Activités https://doi.org/10.4000/activites.1081

Benoit M, Tchamitchian M, Penvern S, Savini I, Bellon S (2017) Potentialités, questionnements et besoins de recherche de l'agriculture biologique face aux enjeux sociétaux. Potentialities, questions and research needs of organic farming in the face of societal challenges. Econ Rural 361:49-69. https://doi.org/10.4000/economierurale.5309

Burton R (2004) Reconceptualising the "behavioural approach" in agricultural studies: a socio-psychological perspective. J Rural Stud 20:359-371. https://doi.org/10.1016/j. jrurstud.2003.12.001

CGAAER (2017) Ambition Bio 2017 program first interim report. http://agriculture.gouv.fr/programme-ambition-bio-2017premier-bilan-intermediaire

Chantre E, Cardona A (2014) Trajectories of French field crop farmers moving toward sustainable farming practices: change, learning, and links with the advisory services. Agroecol Sust Food 38:573-602. https://doi.org/10.1080 $/ 21683565.2013 .876483$ 
Chantre E, Cerf M, Le Bail M (2015) Transitional pathways towards input reduction on French field crop farms. Int $\mathrm{J}$ Agric Sustain 13:69-86. https://doi.org/10.1080 /14735903.2014.945316

Coquil X, Béguin P, Dedieu B (2014) Transition to self-sufficient mixed crop-dairy farming systems. Renew Agr Food Syst 29:195-205. https://doi.org/10.1017/S1742170513000458

Cranfield J, Henson S, Holliday J (2010) The motives, benefits, and problems of conversion to organic production. Agric Hum Values 27:291-306. https://doi.org/10.1007/s10460009-9222-9

Darnhofer I, Bellon S, Dedieu B, Milestad R (2010) Adaptiveness to enhance the sustainability of farming systems. A review. Agron Sustain Dev 30:545-555. https://doi.org/10.1007 /978-94-007-0394-0_4

David C, Mundler P, Demarle O, Ingrand S (2010) Long-term strategies and flexibility of organic farmers in southeastern France. Int J Agric Sustain 8:305-318. https://doi. org/10.3763/ijas.2010.0497

Dessein J, Nevens F (2007) “I'm sad to be glad". An analysis of farmers' pride in Flanders. Sociol Rural 47:273-292. https://doi.org/10.1111/j.1467-9523.2007.00437.x

Doumayzel S (2017) La filière lait de vache biologique (the value chain of organic cow's milk). La Volonté Paysanne. 13 July 2017 , p. 8

European Commission (2016) Evolution of compulsory contracts, producer organisations and the market situation for milk and milk products. Commission Staff Working Document SWD (2016). Brussels. https://ec.europa.eu/agriculture/milk/milk... /com-2016-724_en.pdf

Flaten O, Lien G, Koesling M, Valle PS, Ebbesvik M (2005) Comparing risk perceptions and risk management in organic and conventional dairy farming: empirical results from Norway. Livest Prod Sci 95:11-25. https://doi.org/10.1016 /j.livprodsci.2004.10.014

FNAB (2018) https://www.produire-bio.fr/les-aides/aides-biopdrr-3/

FranceAgriMer (2016) La filière du lait de vache biologique en France (The value chain of organic cow's milk in France). Les Études de FranceAgriMer, édition Décembre 2016. FranceAgriMer, Montreuil

Goulet F, Vinck D (2012) L'innovation par retrait. Contribution à une sociologie du détachement. Innovation by withdrawal. Contribution to a sociology of detachment. Rev française Sociol 53:195. https://doi.org/10.3917/rfs.532.0195

Lamine C (2011) Anticiper ou temporiser: injonctions environnementales. Anticipate or temporize: environmental injunctions. Sociol Trav 53:75-92. https://doi.org/10.1016/j. soctra.2010.12.002

Lamine C, Bellon S (2009) Conversion to organic farming: a multidimensional research object at the crossroads of agricultural and social sciences. A review. Agron Sustain Dev 29: 97-112. https://doi.org/10.1051/agro:2008007

Marshall NA, Tobin RC, Marshall PA, Gooch M, Hobday AJ (2013) Social vulnerability of marine resource users to extreme weather events. Ecosystems 16:797-809. https://doi. org/10.1007/s10021-013-9651-6

Marshall NA, Stokes CJ, Webb NP et al (2014) Social vulnerability to climate change in primary producers: a typology approach. Agric Ecosyst Environ 186:86-93. https://doi. org/10.1016/j.agee.2014.01.004

CA Midi-Pyrénées (2012) Agriculture in Aveyron. www.aveyron. chambagri.fr

Miles M, Huberman A (1994) Qualitative data analysis: An expanded sourcebook. Sage, Thousand Oaks

Milestad R, Darnhofer I (2003) Building farm resilience: the prospects and challenges of organic farming. J Sustain Agric 22:81-97. https://doi.org/10.1300/J064v22n03

Nelson DR, Adger WN, Brown K (2007) Adaptation to environmental change: contributions of a resilience framework. Annu Rev Environ Resour 32:395-419. https://doi. org/10.1146/annurev.energy.32.051807.090348

Olsson P, Folke C, Hughes TP (2008) Navigating the transition to ecosystem-based management of the Great Barrier Reef, Australia. Proc Natl Acad Sci 105:9489-9494. https://doi. org/10.1073/pnas.0706905105

Padel S (2001) Conversion to organic farming: a typical example of the diffusion of an innovation? Sociol Rural 41:40-61. https://doi.org/10.1111/1467-9523.00169

Smit B, Wandel J (2006) Adaptation, adaptive capacity and vulnerability. Glob Environ Chang 16:282-292. https://doi. org/10.1016/j.gloenvcha.2006.03.008

Van der Ploeg JD (2000) Revitalizing agriculture: farming economically as starting ground for rural development. Sociol Rural 40:497-511. https://doi.org/10.1111/1467-9523.00163

Vogl CR, Kummer S, Leitgeb F, Schunko C, Aigner M (2015) Keeping the actors in the organic system learning: the role of organic farmers' experiments. Sustain Agric Res 4:140-148. https://doi.org/10.5539/sar.v4n3p140

Xu Q, Huet S, Poix C, Boisdon I, Deffuant G (2018) Why do farmers not convert to organic farming? Modeling conversion to organic farming as a major change. Nat Resour Model. https://doi.org/10.1111/nrm.12171 